\title{
ПСИХОЛОГИЧЕСКАЯ БЕЗОПАСНОСТЬ СТУДЕНТА В ОБРАЗОВАТЕЛЕНОЙ СРЕДЕ ВУЗА: ПРОСТРАНСТВО СКАЗКОТЕРАПИИ
}

\author{
Мурадян Е.Б. (ЕГУ, Ереван, РА) \\ yelena.muradyan@ysu.am
}

В статье затрагиваются вопросы, касающиеся психологической безопасности студента и психологической безопасности образовательной среды вуза. Анализируется понятие психологической безопасности образовательной среды вуза с учетом ее качественных характеристик и компонентов. Рассматривается возможность разработки психологических технологий по обеспечению психологической безопасности участников образовательной среды в вузе. Обращается внимание на использование сказкотерапевтического тренинга в работе со студентами для достижения ими опыта проживания психологической безопасности.

Ключевые слова: психологическая безопасность, студента, безопасная образовательная среда, вуз, направленность, образование; психотехнология, сказкотерапия.

Обеспечение психологической безопасности личности студента - одна из важнейших задач вузовского образования, связанная с реализацией демократически ориентированной программы гуманизации общественной жизни, в рамках которой в качестве главной ценности для общества рассматривается человек и его достойная жизнь.

Однако кризис в системе образования, проявляющийся и в социальноправовой незащищенности участников образовательного процесса, $и$ в контексте оторванности содержания образования от реальных нужд социума и запросов прогрессивных работодателей, и в недостаточной технологической оснащенности многих вузов, и в технократической направленности образования на фоне нивилирования или деформации духовных, этических и моральных ценностей, и в коммерционализации системы образования, препятствует выполнению вышеуказанной задачи: обеспечение психологической безопасности студента. Логичность подобного вывода подтверждается тем, что психологическая безопасность студента связывается с удовлетворением особых потребностей личности, обусловленных спецификой учебной деятельности, а именно: потребность в получении образования высокого качества, соответствующего запросам современного общества; потребность в условиях, способствующих профессиональному становлению; потребность в профессио- 
нальной компетентности и т.д. [10]. Удовлетворению же этих потребностей, как можно заметить, препятствуют кризисные тенденции в сфере образования.

Таким образом, подобная ситуация негативно отражается на обеспечении психологической безопасности студента, который на протяжении всего учебного процесса оказывается в числе участников образовательной среды вуза и вовлечен в процесс взаимодействия с другими субъектами этой среды, роль которой для человека имеет первостепенное значение для переживания им чувства защищенности, комфорта, отсутствия каких-либо фрорм насилия. Поэтому решение проблемы (хотя бы частичное) относительно декларируемой задачи вуза по обеспечению психологической безопасности студента видится в мероприятиях по созданию психологически безопасной образовательной среды.

Под психологической безопасностью образовательной среды понимается состояние образовательной среды “свободное от проявлений психологического насилия во взаимодействии, способствующее удовлетворению потребностей в личностно-доверительном общении, создающее референтную значимость среды и обеспечивающее психическое здоровье ее участников" [12, с.259]. Однако, в качестве “мерила” сформированности образовательной среды по критерию безопасности/опасности выступает оценка этой среды каждым участником образовательного процесса, а также ее оценка со стороны экспертов. Поэтому психологическая безопасность образовательной среды, как и психологическая безопасность личности зависит от ряда фракторов, рассмотрение которых возможно в континууме объективности - субъективности [1]. Обратимся к некоторым авторским подходам, в которых в качестве критериев безопасности рассматриваются “удовлетворенность настоящим, уверенность в будущем, неснижение вероятности достижения жизненных целей, защищенность интересов, позиций, идеалов, ценностей, с которыми субъект отождествляет свою жизнь” [15]. Также отмечается, что безопасность ассоциируется у людей с комфортом, с защищенностью [17]. В приведенных примерах можно заметить, что акцентируется субъективный оценочный уровень критериев безопасности, связанный с конкретной личностью, что крайне важно, но в то же время недостаточно для адекватной оценки той или иной ситуации в интересующем нас ключе, а именно, с точки зрения безопасности личности в образовательной среде. В этом плане интересен подход к пониманию психологической безопасности личности с учетом объективных факторов, т.е. тех общезначимых, универсальных характеристик среды, наличие которых может способствовать переживанию человеком психологической безопасности [9].

Таким образом, понимание психологической безопасности личности связано как с переживанием человеком собственной экзистенции, с его 
субъективной оценкой той или иной жизненной ситуации, так и с объективной “экспертной” оценкой извне ряда факторов, параметров среды, которые могут или нет выступать в качестве объективных предпосылок, способствующих переживанию человеком психологической безопасности.

В связи со сказанным обратимся К психологической сущности образовательной среды, которая связывается с коммуникативно-деятельностной стороной учебно-воспитательного процесса [12]. В большинстве исследований, направленных на изучение вопросов, связанных с образовательной средой, отмечается ее роль в формировании и развитии личности, а она сама представляется как система, способная в функциональном плане оказывать влияние, создавать условия и возможности для этого [7; 11].

Понимание образовательной среды, как включающей педагогические условия, ситуации, а также “систему отношений между лицами, объединенными общностью педагогической и учебной деятельности” [7, с.25], позволяет расширить ракурс рассмотрения образовательной среды и обратить внимание на ее качественные характеристики с точки зрения психологической безопасности ее участников. К качественным характеристикам образовательной среды предлагается относить: совместную деятельность субъектов образовательной среды (деятельность); наличие субъектов, принимающих участие в образовательном процессе (субъектность); возникновение череды ситуаций, вызванных различными факторами (ситуативность); возможность качественной оценки образовательной среды (оценочность); формирующее воздействие на субъектов среды; возможность воспроизведения главных черт среды при необходимости (проективность); способность к различного рода изменениям (изменчивость, неопределенность); связанность со временем и пространством [7]. Отмечается, что приведенные характеристики образовательной среды есть "суть характеристики ризомности - характерологического свойства современного образования, рассмотренного с позиций неклассической методологии” [7, c.26]. Обратим внимание на такие характеристики среды, как деятельность и субъектность. Как указывалось выше, речь идет о совместной деятельности субъектов образования, т.е. о диалоговом, партнерском типе взаимодействия, субъект-субъектном. Однако в современной системе образования преобладает традиционый способ передачи знаний: трансляция знаний, умений, навыков от обучающего обучаемому, при котором налицо - субъект-объектное взаимодействие, при котором человеку можно привить "рецептурное мышление и стандартные решения на все случаи жизни” [2]. С точки зрения психологической безопасности подобный вектор развития личности гипотетически может быть приемлем только в стабильном мире, тогда как в современном обществе, для которого характерны неопределенность, сложность, разнообразие, система образования должна способствовать развитию человека, готового к вызовам 
времени, к приобретению новых профессий, способного “самостоятельно находить информацию и пользоваться ею”, иметь высокую мотивацию к познанию на протяжении всей жизни. Возможность такого развития личности связывается с системой образования, концептуальной идеей которой станет установка: “учить учиться" [2], а конкретные мероприятия по ее актуализации будут проводиться в соответствующей посылам современности образовательной среде .

Исходя из сказанного, обратимся к научной публикации, в которой представлена разработка технологии создания профессионально и личностно стимулирующей среды вуза, а также выделен компонентно-элементный состав ее базовой структуры, представленный ценностно-смысловым, информационно - содержательным, организационно-деятельностным и пространственнопредметным компонентами [11]. Понимание ценностно-смыслового компонента среды вуза связывается с историей вуза, с определенной концепцией научного вклада вуза в общее образовательное пространство, с его престижностью, спецификой, “геральдикой”, “индивидуальностью”, с традициями, с именами выпускников и преподавателей, имеющих достижения в различных сфрерах профрессиональной, культурной, политической, общественной, духовной жизни социума [11]. Приобщение студента к ценностно-смысловому пространству вуза позволяет ему чувствовать свою значимость и сопричастность к целостной системе, в которую он принят, частью которой он становится, и которая представляется фундаментом, опорой, способной обеспечить чувство защищенности. Все это помогает студенту приобрести уверенность в себе, в своих силах, в собственном ментальном потенциале на фоне доверия вузу как обладающего мощным образовательным потенциалом. Правильная организация процесса вхождения студента в ценностно-смысловое поле вузовской среды при ее достаточной сорормированности будет способствовать переживанию им психологической безопасности.

Принятие студентом ценностно-смыслового компонента вузовской образовательной среды позволяет с доверием отнестись к ее информационносодержательному компоненту, представленому основными и дополнительными профессионально-образовательными программами, реализуемыми в вузе [11]. Инорормационно-содержательный - это базовый компонент вузовской среды, определяющий направленность функционирования вуза для достижения конечной цели - формирования профессионально компетентного выпускника вуза, личности, стремящейся к самоактуализации и самореализации. На сегодняшний день в вузах разрабатываются программы “академического” и “профессионального” типов, также в некоторых вузах практикуется введение “нелинейной” схемы организации учебного процесса, позволяющей предусмотреть возможную образовательную траекторию для каждого студента. Однако 
отмечается, что многие студенты затрудняются в самостоятельном выборе тех дисциплин, которые предлагаются им на выбор, не проявляют достаточной инициативности. В подобной ситуации студентам может предлагаться типовой учебный план данного курса [13]. Особое значение приобретает концептуальный подход к обучению, направленный на развитие учебной мотивации обучающихся, их личностного потенциала, и основывающийся на идее о приоритетности продуктивного, творческого варианта построения учебного процесса [14]. Разработка гибких программ обучения на фоне индивидуального подхода к студенту и организации учебного процесса, способствующего развитию обучающегося благодаря как содержанию образовательных программ, так и стилю взаимодействия, основанного на принципе партнерского, субъект-субъектного взаимодействия между всеми участниками образовательного процесса (организационно-деятельностный компонент образовательной среды вуза), позволят создать наиболее благоприятные условия для обучения студентов в вузе.

Таким образом, формирование и развитие компонентов образовательной среды можно отнести к важнейшей стратегии современного вуза, как системы, которая должна обеспечивать переживание студентом психологической безопасности, как системы, фрормирующей личность профессионала, как системы, способствующей развитию индивидуальности человека, как системы, претворяющей в жизнь принцип: “учить учиться”.

Декларируемую направленность фрормирования психологически безопасной образовательной среды вуза в связи с деятельностью по усовершенствованию вышеперечисленных компонентов среды, можно рассматривать в качестве практической формы реализации идеи по организации профессионально и личностно стимулирующей среды вуза. Технология создания такой среды должна быть представлена совокупностью “средств и способов совместной деятельности субъектов образовательного процесса по проектированию и внедрению элементов, побуждающих студентов и преподавателей к проявлению активности в развитии и саморазвитии своих профессиональноличностных качеств" [11, с.3-4]. С нашей точки зрения, в качестве “побуждающих элементов” возможно использование определенных психотехнологий в работе со студентами. Попытаемся объяснить это, обратившись к пониманию содержательно-функциональной нагрузки термина “психотехнология”.

Несмотря на то, что психотехнология как понятие имеет сложную и неоднозначную трактовку, с характерными интерпретационными “фрлуктуациями” [16], однако по своей сущности, психологические технологии, к разряду которых можно отнести как программы развития личности, так и совокупность различного рода способов, приемов, техник взаимодействия, - это “алгоритм 
решения психологических задач, приводящий к определенному социальному эфроекту" [8].

В рамках нашего исследования в качестве “социального эфффекта” можно рассматривать приобретение человеком опыта переживания психологической безопасности в образовательной среде вуза. Достижению такого эфффекта могут способствовать социально-психологические методы воздействия, например, в фрормате тренинга, являющегося конструктивной, удобной, эффрективной фрормой работы с группой [4]. Также следует отметить, что на сегодняшний день изветны разработки психологических технологий по обеспечению психологической безопасности участников образовательной среды в школе [3]. На наш взгляд, для улучшения качества вузовской образовательной среды, для создания условий, способствующих переживанию учащимися психологической безопасности, в работе со студентами также необходимо проведение соответствующих мероприятий. Особый интерес, в этом ключе, может представлять разработка тренинговой программы на основе метода сказкотерапии с использованием соответствующих техник.

Обращение именно к сказкотерапии связано со спецификой этого метода, с его особенностями, с возможностью создания особой сказочной среды, в которой, “появляется чувство защищенности” [6, с. 14]. Кроме того, сказка, сказочные техники знакомы и понятны всем, сказочное поле обеспечивает комфорт и безопасность студента, метод сказкотерапии позволяет подготовить человека к неожиданностям, абсурдным ситуациям, так как в основе главного “инструмента" этого метода - сказке, изначально заложено фрилософское понимание “абсурда”.

В связи со сказанным, обратимся к замечательной идее А. Г. Асмолова о “сказочной” логике развития современной системы образования: “возможность смело браться за решение задач русских сказок “пойди туда, не знаю куда, найди то, не знаю что” - это путеводная линия для понимания того, каким должно быть образование в XXI веке” [2]. Заметим, что приведенная сказочная метафора, как нельзя более соответствует задачам, стоящим перед современным человеком, а приоритетность отмеченной траектории развития образования объясняется особенностями современного мира, характеризующегося “неопределенностью”, “сложностью”, “разнообразием”, а также “многозадачностью” [2]. Для жизни в таком мире Человеку необходимо быть готовым к любым “вызовам” современности и обладать определенными качествами, развитию которых, во многом, может способствовать именно сказкотерапевтический тренинг в контексте Комплексной сказкотерапии.

Становление концепции Комплексной сказкотерапии как отдельного направления в психотерапии (Основоположником этого направления является Зинкевич-Евстигнеевой Т. Д.) связано “с духовным подходом к сказкам, с 
пониманием сказкотерапии как природосообразной, органичной человеческому восприятию воспитательной системы, проверенной многими поколениями наших предков" [6, с. 14]. Сказки способствуют развитию воображения, творческого потенциала личности; с помощью сказки возможно философское осознание окружающей нас действительности, переосмысление существующей и порождение новой “картины мира”. Язык сказки метафоричен, т.е. недирективен, он затрагивает не только поведенческие аспекты, но и ценностную структуру психики человека и, что самое важное, “создает вокруг человека ауру психологической защищенности" [5, с. 16].

Понимание Комплексной сказкотерапии связано с многообразием заложенных в ней концептуальных положений из различных направлений психологии, с эклектичностью техник и возможностью нахождения смыслов, скрытых в сказках, без каких-либо интерпретационных “рамок” и ограничений. Поэтому определение сказкотерапии в плане функционально-содержательной нагрузки крайне неоднозначно.

Так сказкотерапию определяют и как лечение сказками, при котором появляется возможность открытия человеком в себе тех знаний, которые являются психотерапевтическими; и как процесс поиска смысла, сущностных характеристик бытия и системы взаимоотношений в нем; и как процесс осознания и выявления связи между сказочными событиями и реальностью; и как процесс, способствующий активизации и актуализации значимого в социально-психологическом аспекте потенциала личности; и как терапию особой сказочной средой, в которой идет “процесс экологического образования и воспитания”, появляется возможность реализации мечты [6, с. 8-14].

Таким образом, использование метода сказкотерапии в работе со студентами будет способствовать созданию позитивной, творческой, комфортной и безопасной среды в образовательном учреждении, нахождение в которой позволит студенту приобрести опыт проживания психологической безопасности. Приобретенный опыт может стать нормативным и позволит студенту справляться на личностном уровне с негативными характеристиками образовательной среды, с одной стороны, а также принимать активное участие в преобразовании этой среды, стараясь сделать ее психологически безопасной.

\section{Литература}

1. Агузумцян Р.В., Мурадян Е.Б. Психологические аспекты безопасности личности // Вестник практической психологии образования/2009. - N1(18) - c.43-47.

2. Асмолов А.Г. Образование впереди перемен: школа неопределенности / (https://postnauka.ru/talks/84112. Дата обращения: 30.04.2018) 
3. Баева И.А. Тренинги психологической безопасности в школе.- СПб.: Речь, 2002. - 251c.

4. Вачков И.В. Основы технологии группового тренинга. Учеб. Пособие М.: Изд-во “Ось-89”, 1999.-176с.

5. Зинкевич-Евстигнеева Т.Д. “Путь к волшебству” - СПб.: “Златоуст”, 1998.- 352c.

6. Зинкевич-Евстигнеева Т.Д.. Практикум по сказкотерапии: - СПб.: 000 “Речь", 2000 -310с.

7. Иванова С.В. Образовательное пространство и образовательная среда: в поисках отличий // Ценности и смыслы. 2015. N6(40). URL: https://cyberleninka.ru/article/n/obrazovatelnoe-prostranstvo-iobrazovatelnaya-sreda-v-poiskah-otlichiy. (дата обращения:10.05.2018)

8. Кабаченко Т.С. Методы психологического воздействия/ M.: Педагогическое общество России.- 2000.-544c., с.102-103.

9. Лебедева Л.Д. Психологическая безопасность личности в арттерапевтической работе / (https://lib.druzya.org/art-ter/.view-lebedevaart.txt.html?pg=1. Дата обращения: 2.06.2018)

10. Мурадян Е.Б. Роль психологии в филологическом образовании: возможность обеспечения психологической безопасности студентафрилолога посредством сказкотерапии. Актуальная психология. Научный вестник/ 2017. - N1, с. 530-535.

11. Новиков В.Н. Образовательная среда вуза как профессионально и личностно стимулирующий фрактор / Электронный журнал “Психологическая наука и образование”, N1, 2012/ (http://psyedu.ru/journal/2012/1/2776.phtml. Дата бращения: 15.04.2018)

12. Обеспечение психологической безопасности в образовательном учреждении: практическое руководство/под ред. И.А. Баевой. - СПб.: Речь, 2006. - 288c.

13. Особенности организации учебного процесса в российских и зарубежных вузах в свете текущей реформы ВПО. Аналитическая записка. РГГУ 2006 (www.rsuh.ru/binary/56682_65.1173464770.37153.doc. Дата обращения: 30.03.2018)

14. Педагогика и психология высшей школы. - Ростов-на-Дону: “Феникс".1998.-544c.

15. Психология личности. Учебное пособие/ под ред. проф. П.Н. Ермакова, проф. В.А. Лабунской. - М.: Эксмо.- 2007.- 578с.

16. Узлов Н.Д. Психотехнология: к проблеме определения понятия/ Вестник Пермского университета/Выпуск 1(5), 2011.- с.32-42 
17. Харламенкова Н.Е. Личностная безопасность и стратегии ее достижения // Проблемы психологической безопасности / Отв.ред. А.Л. Журавлев, Н.В. Тарабрина. М.: Изд-во “Институт психологии РАН”/ 2012.- с.133-160.

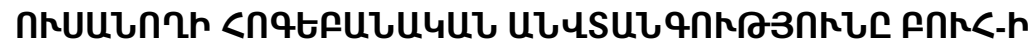

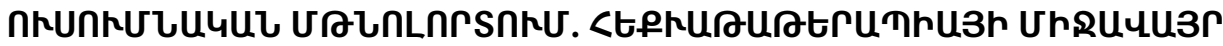

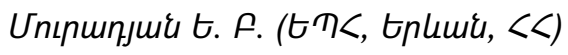

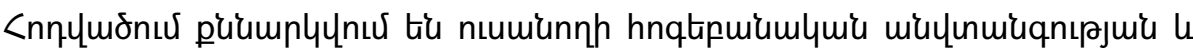

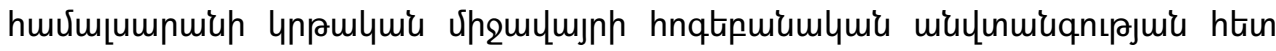

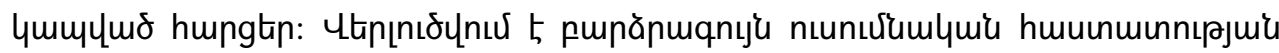

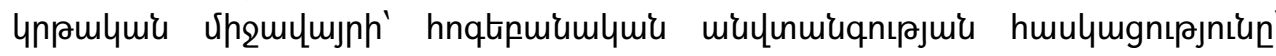

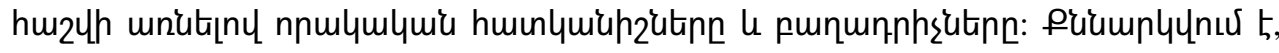

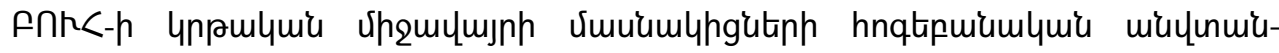

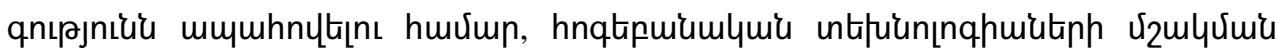

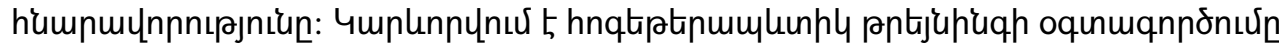

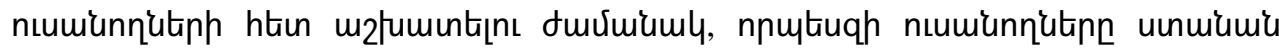

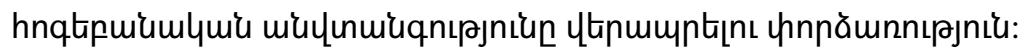

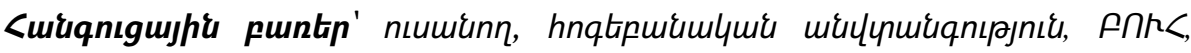

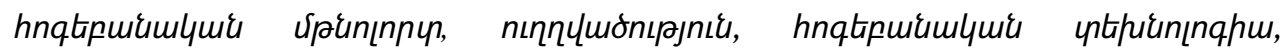

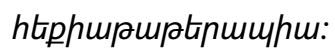

\section{PSYCHOLOGICAL SAFETY OF THE STUDENT IN THE EDUCATIONAL ENVIRONMENT OF THE UNIVERSITY: THE SPACE OF FAIRY-TALE THERAPY}

Muradyan Ye. B. (YSU, Yerevan, RA)

The article touches upon the issues concerning the psychological safety of the student and the psychological safety of the educational environment of the university. The concept of psychological security of the educational environment of the university is analyzed taking into account its qualitative characteristics and components. The possibility of developing psychological technologies to ensure psychological safety of participants in the educational environment in the university is considered. Attention is drawn to the use of fairy tale -therapeutic training in working with students to achieve their experience of living psychological safety.

Key words: student, psychological safety, psychologically educational environment, university, the direction of education, psychotechnology, fairy tale therapy. 